\title{
Using genre pedagogy to promote student proficiency in the language required for interpreting line graphs
}

\author{
Jantien Smit ${ }^{1,2}$ - Arthur Bakker ${ }^{2}$ (D) \\ Dolly van Eerde ${ }^{2} \cdot$ Maggie Kuijpers $^{2}$
}

Received: 20 December 2015 /Revised: 31 July 2016 / Accepted: 3 August 2016/

Published online: 27 August 2016

(C) The Author(s) 2016. This article is published with open access at Springerlink.com

\begin{abstract}
The importance of language in mathematics learning has been widely acknowledged. However, little is known about how to make this insight productive in the design and enactment of language-oriented mathematics education. In a design-based research project, we explored how language-oriented mathematics education can be designed and enacted. We drew on genre pedagogy to promote student proficiency in the language required for interpreting line graphs. In the intervention, the teacher used scaffolding strategies to focus students' attention on the structure and linguistic features of the language involved in this particular domain. The research question addressed in this paper is how student proficiency in this language may be promoted. The study comprised nine lessons involving 22 students in grades 5 and 6 (aged 10-12); of these students, 19 had a migrant background. In light of the research aim, we first describe the rationale behind our design. Next, we illustrate how the design was enacted by means of a case study focusing on one student in the classroom practice of developing proficiency in the language required for interpreting line graphs. On the basis of pre- and posttest scores, we conclude that overall their proficiency has increased. Together, the results indicate that and how genre pedagogy may be used to help students become more proficient in the language required in a mathematical domain.
\end{abstract}

Keywords Genre pedagogy · Design study · Graphs · Mathematical language · Scaffolding · Teaching and learning cycle

Arthur Bakker

a.bakker4@uu.nl

Jantien Smit

j.smit@saxion.nl

1 Saxion University of Applied Sciences, Postbus 70.000, 7500 KBEnschede, The Netherlands

2 Utrecht University, Princetonplein 5, 3584 CCUtrecht, The Netherlands 
Language is one of the key semiotic systems operating in mathematics (Schleppegrell 2007). Some scholars go so far as to claim that mathematics is a language (e.g., Mousley and Marks 1991), suggesting that if students "talk" the language of a mathematics domain, they have access to its content. Despite different understandings of the relationships between mathematics and language, there is widespread consensus on language playing a vital role in mathematical learning (Chapman 2003; Ellerton and Clements 1991; Lampert and Blunk 1998; Moschkovich 2010; Mushin et al. 2013; Pimm 1987; Planas and Setati 2009; Sfard 2008; Wilkinson 2015).

Most existing research on the relationship between mathematics and language describes and explains mathematical learning as it happens in naturalistic settings. It is known that explicit attention to language is supposed to provide students with access to the official discourses of the classroom (Hyland 2004; Morgan 2007) and thus forms the gateway to better educational and societal opportunities for immigrant students but also supports native students (e.g., Adler 2001; Campbell et al. 2007; Schleppegrell 2007). Far less is known about how to design and enact language-oriented mathematics education (Mousley and Marks 1991; Prediger and Wessel 2013; Warren and Miller 2013) so more interventionist research in this area is necessary (as observed by Ellerton and Clarkson, 1996, and Moschkovich, 2010). Our approach to language-oriented mathematics education was informed by the Sydney School of genre pedagogy (Martin 1989, 2009). The core idea of genre pedagogy is to focus explicitly on the ways language can be used to achieve purposes in particular contexts (Gibbons 2002; Hyland 2007).

The purpose of our design-based research project was thus to gain insight into how to design and enact language-oriented mathematics education. We ask: How can genre pedagogy be used to promote student proficiency in the language required to interpret line graphs?

To answer this question, we undertake three main steps. First, we present the rationale behind our approach. We draw on genre pedagogy and underpin the learning goals as well as the design principles and teaching strategies, such as scaffolding, deployed in the domain of line graphs. We did not use a control group because comparison to another group that did not aim to achieve the same (new) learning goals would not have made sense. Second, we present a case study focusing on one student to illustrate how the approach was enacted. Last, we show to what extent the approach promoted student proficiency in the language required to interpret line graphs.

\section{Theoretical background of the design and enactment}

\section{Genre pedagogy: making language for learning explicit}

Genre pedagogy offers the conceptual means (e.g., genre) and pedagogical tools (e.g., teaching and learning cycle) to take a functional perspective on language use and to promote student proficiency in the language required within a particular domain, in our case line graphs. Spycher (2007) defined genres as "socially recognized ways of using language that enable people to say things about the world, establish relationships, and accomplish tasks" (pp. 240-241). Although some genre scholars adhere to defining genre solely in terms of social processes, we focus on genres as textual products of a social process (cf. Knapp and Watkins 2005) that can be enacted either in speaking or in 
writing. Such texts are staged, which refers to how meanings in text types are phased through stages in reasonably predictable ways, represented in a schematic structure (Martin and Rose 2008). A written report, for example, usually starts with an opening statement, general classification, or definition, followed by facts about various aspects of the subject (Derewianka 1990). Such a schematic structure is captured in structure features, referring, for example, to sequencing aspects of a text or to which crucial content elements should be included. Linguistic features concern text conventions, such as particular formulations (Chapman 2003; Cope and Kalantzis 1993). Genre scholars share the assumption that the structure and linguistic features of genres for schooling need to be taught and learned explicitly, in particular in multilingual classrooms.

When drawing on genre pedagogy to support students' proficiency in the language required for interpreting line graphs, we first felt the need to formulate languageoriented learning goals, informed by the mathematical nature of the domain (next section), challenges and difficulties typically experienced by students, as well as the types of language needed for describing and interpreting line graphs (following sections). In a subsequent step, we specify the features of the language to be promoted.

\section{Toward language-oriented learning goals for interpreting line graphs}

The research project focused on interpreting line graphs that show change over time. Graphs are not only fundamental in mathematics but also indispensable in the fields of physical and social sciences (Nathan and Kim 2007). Line graphs, at least at the primary and middle school level, typically represent data of real-world phenomena (e.g., Clarke 1988; Lovitt and Clarke 2011). Leinhardt et al. (1990) consider graphs "communicative systems, on the one hand, and a construction and organization of mathematical ideas on the other" (p. 3). In the same review, they stated that graphs could have a bridging function between reasoning from the concrete to the abstract. Monk (2003) also pointed toward such a distinction between the abstract and the concrete in his observation that students can build understanding of the graph and its context simultaneously by exploring both: "A graph can be used both as a window into a phenomenon and as a world of meanings in its own right" (p. 256). Focus on the language involved in interpreting line graphs should provide access to reasoning in the domain of line graphs so that students can express relations between the natural phenomena represented and the mathematical phenomena. Hence, we formulated learning goal 1: Students can describe line graphs and interpret natural phenomena represented in graphs.

Students have been found to experience many difficulties in the domain of line graphs (cf. Leinhardt et al. 1990). Leinhardt et al. distinguished between pointwise reading of graphs and relative (across-time) reading and interpretation. We use Fig. 1 to illustrate related difficulties. A question that elicits pointwise reading is "How much does Uncle Kees weigh when he is 35 years old?" A question that elicits across-time reading is: "What happens to Uncle Kees' weight between his 30th and his 35th birthday?" Leinhardt et al. revealed that students tend to maintain focus on individual points in the graph, even if these points are connected with a line: “... although lines are accepted as a legitimate part of graphs, they seem to serve a connecting function rather than possessing a meaning in their own right" (p. 34). Similarly, Monk (2003) stated that students found across-time questions far more difficult to answer than pointwise 
Uncle Kees' weight

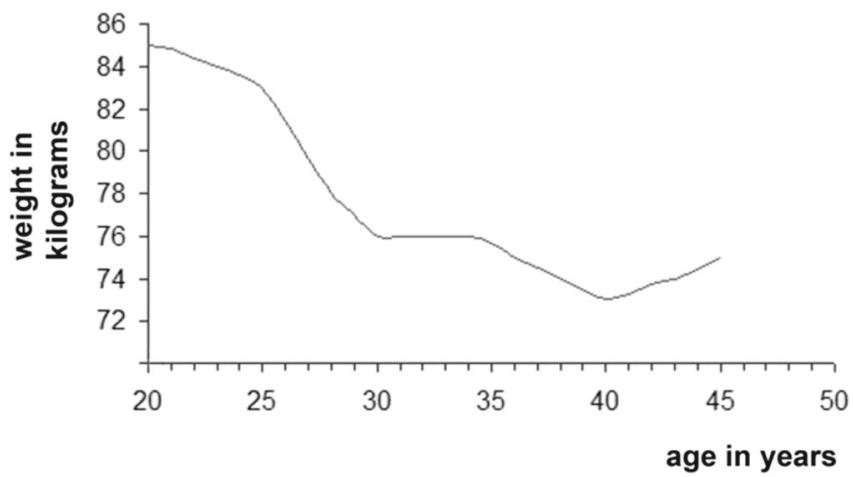

At the age of 20, Uncle Kees weighs 85 kilograms. Between his 20th and his 25 th birthday, he slowly loses weight. The graph descends gradually. Between his 25 th and his 30th birthday his weight decreases quickly. You can tell as the graph shows a steep fall. From his 30th to his 35 th birthday his weight remains more or less the same. The graph is constant. Between his 35 th and his 40 th birthday he slowly loses weight; the graph gradually descends. When Uncle Kees is 40 his weight reaches its minimum: about 74 kilograms. From the age of 40 on his weight increases slightly. In this part, the graph gradually rises.

Fig. 1 Line graph and exemplary text including structure and linguistic features

questions. Another difficulty includes students' tendency to regard graphs as entities that embody causalities (Leinhardt et al. 1990); for example, "Uncle Kees became heavier because he ate too much." What is also relevant to across-time reading of graphs is students' difficulty with understanding constant functions, as students tend to view only changing quantities as legitimate. Interpreting gradations of a graph's steepness has also been addressed as challenging for students (cf. Moschkovich 1996; Shah and Hoeffner 2002). Taking these difficulties together, we concluded that we should focus explicitly on the links between visual features (e.g., steepness, gradual increase) and their meaning. In grades 5 and 6 , we focused on such qualitative graph features as preparation for more advanced quantitative reasoning about line graphs in secondary education. For example, the quantitative notion of slope is not introduced in the Dutch mathematics curriculum until grade 8 (Expertgroep Taal en Rekenen 2009). These considerations led to the formulation of learning goal 2: Students can express both pointwise and relative (here, across-time) reading of line graphs.

Native speakers tend to develop general academic language as a by-product of classroom participation, implying that for them, this type of language typically does not need explicit attention. However, for second language learners and language-weak native students, this is mostly not the case (e.g., Gibbons 2002). Being familiar with everyday discourse and general academic language (e.g., to be able to reason about increase, growth, and process) has been argued to support the development of topic-specific mathematical language (Ferrari 2004; Gutiérrez et al. 2010; Moschkovich 2002; Setati and Adler 2000). Hence, all three types of language (everyday, general academic, and topic-specific) require attention in language-oriented mathematics education.

Concerning the interpretation of line graphs, we investigated what particular language students needed to distinguish between moments and periods in time (i.e., to distinguish between pointwise and across-time reading). We concluded that temporal prepositions (e.g., from...to, between...and, at, in) are a key to 
being mathematically precise in the domain of line graphs, as they allow for distinguishing between moments and periods in time. It is likely that without the linguistic tools to distinguish between moments and periods in time (i.e., points and segments of the graph), students will find it difficult to reason with the concepts involved (e.g., an on-the-spot measurement versus changes over time). The literature on second language learners' problems shows that prepositions are particularly challenging (e.g., Chodorow et al. 2010). Hence, we paid special attention to prepositions in designing for learning goal 3: Students can deploy everyday (e.g., temporal prepositions), general academic, and topic-specific mathematical language required to interpret line graphs.

\section{Features of the required language}

In this subsection, we describe specifications of the learning goals in terms of structure features and linguistic features of the language in which we intended students to become proficient (Table 1). These features were the yield of three cycles of designbased research. In Table 1, a segment of a graph refers to a part of the graph in which its direction shows little or no change. We formulated two structure features to meet learning goal 1:

- Each segment of the graph is interpreted in terms of what happens in reality (structure feature 1, abbreviated as S1).

- Each segment of the graph is described in terms of the course of the graph (structure feature 2, S2).

To interpret and describe segments, students need specific language. In line with learning goal 3 on everyday, general academic, and topic-specific language, we formulated two linguistic features:

- For interpreting reality, general academic language is used (linguistic feature 1, abbreviated as L1).

- For describing the course of the graph, topic-specific mathematical language is used (linguistic feature 2, L2).

Pointwise reading, in general, and the inclusion of starting points, peaks, and troughs, in particular, are important to describe critical moments in the natural phenomena. Therefore, we also included the following structure features concerning points in a line graph:

- The starting point of the graph is described (structure feature S3).

- When present in the graph, peaks and troughs are described (structure feature S4).

To meet learning goal 2 concerning across-time reading of graphs in relation to the natural phenomena the graphs represent, we needed to formulate a linguistic feature that would help students interpret and describe gradations of a line graph's steepness in a mathematically precise way: 
Table 1 Structure and linguistic features of the language required for interpreting line graphs

\begin{tabular}{|c|c|c|}
\hline & Structure features & Examples \\
\hline S1 & $\begin{array}{l}\text { For interpreting reality, general academic } \\
\text { language is used }\end{array}$ & $\begin{array}{l}\text { "Between his } 25 \text { th and his } 30 \text { th birthday } \\
\text { his weight quickly diminishes." }\end{array}$ \\
\hline $\mathrm{S} 2$ & $\begin{array}{l}\text { Each segment of the graph is described in } \\
\text { terms of the course of the graph }\end{array}$ & "The graph descends gradually." \\
\hline $\mathrm{S} 3$ & The starting point of the graph is described & $\begin{array}{l}\text { "At the age of } 20 \text { Uncle Kees weighs } 85 \\
\text { kilograms." }\end{array}$ \\
\hline \multirow[t]{2}{*}{ S4 } & $\begin{array}{l}\text { When present in the graph, peaks and } \\
\text { troughs are described }\end{array}$ & $\begin{array}{l}\text { "When Uncle Kees is } 40 \text {, his weight } \\
\text { reaches its minimum: about } 74 \\
\text { kilograms." }\end{array}$ \\
\hline & Linguistic features & Examples \\
\hline L1 & $\begin{array}{l}\text { For interpreting reality, general academic } \\
\text { language is used }\end{array}$ & "...his weight decreases quickly" \\
\hline $\mathrm{L} 2$ & $\begin{array}{l}\text { For describing the course of the graph, } \\
\text { topic-specific mathematical language is } \\
\text { used }\end{array}$ & "Descends gradually" \\
\hline L3 & $\begin{array}{l}\text { Gradations (e.g., of steepness) are } \\
\text { expressed to realize mathematical } \\
\text { precision, though not yet in numeric } \\
\text { form }\end{array}$ & $\begin{array}{l}\text { "The graph shows a steep fall." } \\
\text { "The graph descends gradually." } \\
\text { "He slowly loses weight." }\end{array}$ \\
\hline L4 & $\begin{array}{l}\text { Student uses words such as as, at, in, and } \\
\text { when to refer to moments in time (i.e., } \\
\text { points in the graphs) }\end{array}$ & $\begin{array}{l}\text { "At the age of } 20 " \\
\text { "In 2010" }\end{array}$ \\
\hline L5 & $\begin{array}{l}\text { Student uses word combinations such as } \\
\text { from ...to, between...and, and from ... } \\
\text { onward to refer to periods in time (i.e., } \\
\text { segments of the graph) }\end{array}$ & $\begin{array}{l}\text { "Between his 20th and his 25th birthday" } \\
\text { "From } 2010 \text { to } 2012 "\end{array}$ \\
\hline
\end{tabular}

- Gradations (e.g., of steepness) are expressed to realize mathematical precision, though not yet in numeric form (linguistic feature L3). Examples of words that support such reasoning are gradually, fast, slowly, and steep.

We further formulated particular linguistic features to serve as tools with which students could adequately refer to and distinguish between moments and periods in time:

- Student uses words such as as, at, in, and when to refer to moments in time (i.e., points in the graphs; linguistic feature L4).

- Student uses word combinations such as from ...to, between ... and, and from... onward to refer to periods in time (i.e., segments of the graph; linguistic feature L5).

The formulations of these features were intended to provide teachers with conventions to be established in the classroom and students with tools for reasoning about line graphs. 


\section{Scaffolding: design and teaching}

Within genre pedagogy, the idea of scaffolding is often used (Gibbons 2002). Scaffolding (Wood et al. 1976) refers to temporary help that is provided by a more knowledgeable other to help a learner perform a task. The use of the scaffolding concept has been extended to a variety of settings including mathematics education (Bakker et al. 2015; Bickmore-Brand and Gawned 1990). A consequence of this widening of the concept's scope is that scaffolding can be distributed not only across agents such as teachers, design, and artifacts, but also to the whole-class setting (Smit et al. 2013). This conceptualization of whole-class scaffolding underlies the current study (Bakker and Smit 2016). Based on the scaffolding literature, three key characteristics of scaffolding are distinguished: diagnosis, responsiveness (the adaptive core of the support provided), and handover to independence. In our case, the overarching design principle is that over time, students express themselves more independently in appropriate language related to line graphs. To this end, we employed the idea of the teaching and learning cycle as articulated in genre pedagogy.

\section{Teaching and learning cycle}

To promote proficiency in the required language, we deployed the teaching and learning cycle, also known as the curriculum cycle, as a design heuristic in our lesson design (Derewianka 1990; Gibbons 2002; Rothery 1996). The purpose of the teaching and learning cycle is to induct students in written-like, academic language use (or, more generally, genres) needed for participating throughout the curriculum. The teaching and learning cycle consists of four phases through which the structure features and linguistic features of a particular genre can be made explicit to students. Each of the phases has a specific teaching purpose (Gibbons 2009) and informs the planning of classroom activities related to different teacher-learner roles (Hyland 2007). The overall structure of the teaching and learning cycle is inspired by the idea of scaffolding.

In the first phase, building the field, students and teachers explore the context in which a genre is to be used to build up common basic understandings. In the second phase, the modeling phase, purpose, structure features, and linguistic features of the genre are explored by means of sample texts or modeling activities (e.g., writing activities by using writing frames in which parts of sentences are left out). During the third phase of joint construction, a teacher demonstrates both the process and product of writing in the genre based on suggestions from students. In the fourth phase, independent writing, students are expected to draw on their learning in the previous three phases and to write in the genre without support by either the teacher or models. In line with the idea of scaffolding, this independence is the final stage of gradually withdrawn support and direct instruction.

\section{Scaffolding strategies}

To enact this general design principle in the classroom, the teacher was asked to enact scaffolding strategies that were formulated, enacted, and tested in an earlier phase of the design-based research project reported here (Smit and Van Eerde 2011). These strategies involved diagnosis of the quality of the mathematical language used by 
students and involved responsive actions with the intention to make students independent users of precise language (cf. Chapman 1997). Strategies that the teacher used to promote students' proficiency in the language required for interpreting line graphs are summarized in Table 2.

\section{Methods}

In the previous section, we have summarized how genre pedagogy has informed our design. To address the research question of how genre pedagogy can be used effectively to promote student proficiency in the language required to interpret line graphs, two further steps are required. To give the reader a qualitative sense of how student proficiency was promoted, we present a case study of a student, Abdul, in the classroom practice of developing proficiency in the language required for interpreting line graphs. Next, we present an analysis of pre- and posttest data to check to what extent the approach was effective.

\section{Participants}

\section{Classroom}

The school was a multilingual school in a neighborhood with a low socioeconomic status. In the particular classroom studied, students did not only seem to work in groups, but also as groups (cf. Mercer and Littleton 2007). That is, students seemed to contribute actively to small group discussion and to negotiate mathematical solutions that were written on the window with specific writing pens

Table 2 Strategies for scaffolding language and examples for each strategy

\begin{tabular}{|c|c|c|c|}
\hline & Abbreviations & Strategies & Examples \\
\hline 1 & RefExt & $\begin{array}{l}\text { Reformulate or extending students' spoken } \\
\text { or written utterances }\end{array}$ & $\begin{array}{l}\text { [In response to "the graph goes higher } \\
\text { and higher up":] "Yes, the graph does } \\
\text { rise steeply." }\end{array}$ \\
\hline 2 & LingFea & $\begin{array}{l}\text { Explicitly referring to or reminding of linguistic } \\
\text { features (e.g., topic-specific words or tempo- } \\
\text { ral prepositions), doing so implicitly by re- } \\
\text { ferring to or pointing at the word list, or by } \\
\text { referring explicitly to supportive gestures }\end{array}$ & $\begin{array}{l}\text { "Look, the word you are looking for is } \\
\text { written down here." }\end{array}$ \\
\hline 3 & StrucFea & $\begin{array}{l}\text { Explicitly referring to or reminding of structure } \\
\text { features (e.g., the use of a specific type of } \\
\text { language such as topic-specific language) }\end{array}$ & $\begin{array}{l}\text { "Into how many segments can we split } \\
\text { the graph?" }\end{array}$ \\
\hline 4 & AskImp & $\begin{array}{l}\text { Asking students to improve language (e.g., } \\
\text { asking for more precise language) or to } \\
\text { elaborate their utterance }\end{array}$ & $\begin{array}{l}\text { "How can we rewrite this in more } \\
\text { mathematical language?" }\end{array}$ \\
\hline 5 & RepCor & Repeat correct student utterances & "Yes, the graph does descend slowly." \\
\hline 6 & IndPro & $\begin{array}{l}\text { Asking for or explicitly encouraging students to } \\
\text { independently produce spoken or written } \\
\text { language }\end{array}$ & $\begin{array}{l}\text { "And now try to formulate a sentence } \\
\text { yourself." }\end{array}$ \\
\hline
\end{tabular}


(and wiped out if a better solution was suggested by another student). Moreover, students seemed to value each other's contributions and so did the teacher. It has been argued that social norms like these are a prerequisite for meaningful wholeclass discussion in which students dare to speak (Cobb and Yackel 1996). The regular class teacher seemed to have a positive attitude toward the students and seemed to express high expectations of them (cf. Gibbons 2002). All in all, we think that the school culture was supportive to our research aim because students responded positively to the attention given to language in the mathematics lessons on graphs from the very beginning of the intervention.

The design study analyzed here was carried out in grades 5 and 6 (aged 10-12) and comprised nine lessons - one per week — of about 60 min each. The classroom consisted of 22 students, 19 of whom were second language learners. Eighteen of these were second- and third-generation Moroccan and Turkish students, and one came from Iran. Some students spoke Dutch at home, others Berber or Turkish.

\section{Teacher}

The teacher was not employed at the school involved in the research project. We asked her to participate because she had 17 years of experience in primary education, partly in multilingual classrooms. In the following, we will refer to the participating teacher as "teacher" and to the regular teacher of the primary class as "class teacher."

\section{Abdul}

One reason for selecting Abdul (pseudonym) for the case study was to illustrate the potential progress of a lower-level achieving student. Furthermore, he talked enough during whole-class settings to be interesting for such an analysis. During a stimulated recall interview, the teacher had said about him that he used slang and she was worried he would have trouble developing the intended general and topicspecific language. The class teacher also considered him a mathematically weak student with language problems. Abdul's proficiency progress thus serves as an interesting case for qualitative characterization.

\section{Instruments}

\section{Pre- and posttest items}

For the analysis of the effectiveness of the approach, we used comparable preand posttest items to determine the extent to which students had made progress in the mathematical language required for interpreting line graphs. In these items, students were asked to independently make a line graph interpretation and description (see Fig. 2). There were 8 days between the last lesson and the posttest.

Students had to describe and interpret a line graph such as Fig. 1 shows, which took them up to $15 \mathrm{~min}$ (about one third of the total test). Another part of the tests, on receptive language learning, was analyzed in Smit and Van Eerde (2013). 


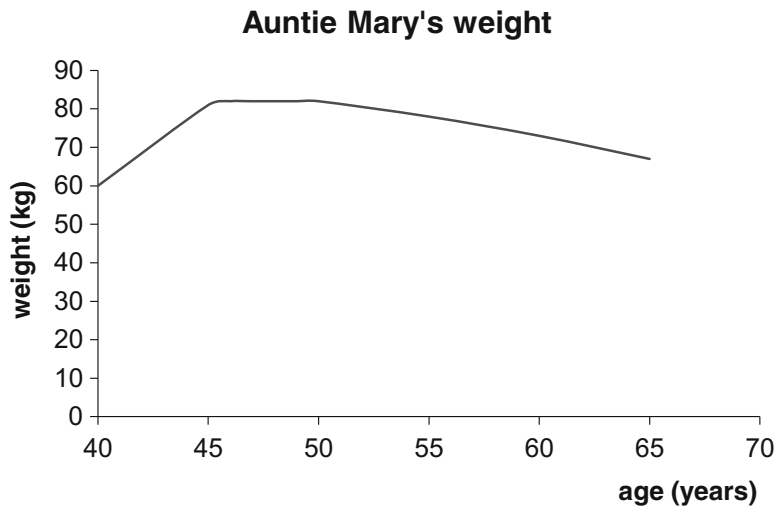

Describe how Auntie Mary's weight changes and how you can tell from the graph.

Fig. 2 Test item for investigating student proficiency in the language required for interpreting line graphs

\section{Data collection}

The collection of data used for the analyses presented in this paper included audio and video recordings of nine lessons (all transcribed verbatim), field notes, students' preand posttest results, as well as their written work.

\section{Data analysis}

\section{Case study}

In this case study, we paid attention to the structure features and linguistic features of the language used to describe and interpret line graphs and their relation to the enacted scaffolding strategies. About $60 \%$ of each lesson was devoted to wholeclass interaction. To characterize Abdul's developing language proficiency in whole-class interaction, we first identified all his utterances in the lesson transcripts. Next, we conducted a qualitative analysis of Abdul's utterances throughout the lessons in terms of structure and linguistic features. Incidents concerned particular structure and linguistic features of the use of language, related to his understanding of mathematical content. One author's chronological reading of these incidents led to conjectures that she triangulated with other data we had about Abdul. Confirmed conjectures remained; unconfirmed conjectures were rejected. This qualitative analysis of Abdul's classroom utterances in relation to our theoretical framework was checked by another author. Based on her reading of the analysis conducted by the first author, she suggested a few minor reformulations. The gradual development of Abdul's language proficiency throughout the stages of the teaching and learning cycle was judged valid by her.

This case study is structured chronologically according to the four phases of the aforementioned teaching and learning cycle. Other aspects of the intervention (e.g., scaffolding strategies) are mentioned when relevant within the qualitative analysis of Abdul's development. In parentheses, we refer to structure and linguistic features as presented in Table 1. 


\section{Pre-posttest analysis}

Last, we analyzed all students' writing in the targeted text type in pre- and posttest. These tests consisted respectively of nine and eight items and lasted up to $50 \mathrm{~min}$ (pretest) and $45 \mathrm{~min}$ (posttest). The test items were constructed so as to gain insight into mathematical understanding of line graphs and into both receptive and productive language proficiency. The item that we used for analyzing students' writing performance is shown in Fig. 2.

We developed an analytic framework for assessing students' written mathematical and linguistic performance that included scoring instructions and fictitious examples. After several rounds of constructing, testing, and evaluating the framework, the final 12 categories of the analytic framework were formulated, capturing all structure and linguistic features. Ten out of 12 categories have an ordinal threepoint scoring system (see Table 3 ). The remaining two categories involved the counting of general academic words (e.g., increase, decrease, grow, equal) and topic-specific words (e.g., constant, gradually, rise, descend) that students used in their written texts (a ratio scoring system).

All students' line graph descriptions in pre- and posttest were scored by two independent raters using the analytic framework. As a consequence of using two different scoring systems (ordinal and rational), we computed two kappas (one for each scoring system) to determine interrater reliability. Cohen's kappa, computed on 418 ordinal units, was .77. Cohen's kappa, based on 88 ratio units, was .78. Both kappas indicate substantial interrater reliability (Cohen 1988).

To determine students' language proficiency in pre- and posttests, all students received a mark (1 to 10) for their written graph descriptions, based on the following steps. First, for each unit to be scored, the arithmetic mean of two scores attributed by the independent raters was determined. Subsequently, these mean scores were multiplied by the weight attributed to each particular category by the researchers. For example, the category of "describes each segment in terms of what happens in reality" was attributed more weight (3) than the category of "describes the starting point of the

Table 3 Example of a category from the analytic framework in scoring pre- and posttest items

\begin{tabular}{|c|c|c|c|c|}
\hline Category & Score & Description for each score & Scoring instruction & Example \\
\hline \multirow{3}{*}{$\begin{array}{l}\text { Describes the } \\
\text { starting } \\
\text { point of the } \\
\text { line graph }\end{array}$} & 1 & $\begin{array}{l}\text { The starting point has not } \\
\text { been described }\end{array}$ & $\begin{array}{l}\text { No data involving the starting } \\
\text { point of the line graph are } \\
\text { included }\end{array}$ & \\
\hline & 2 & $\begin{array}{l}\text { The starting point has } \\
\text { been described, but } \\
\text { either incorrectly or } \\
\text { incompletely }\end{array}$ & $\begin{array}{l}\text { Only one of the two axes is } \\
\text { included in the description of } \\
\text { the starting point on the line } \\
\text { graph. } \\
\text { One axis is incorrectly } \\
\text { interpreted }\end{array}$ & $\begin{array}{l}\text { "Uncle Jan weighs } \\
80 \text { kilos." } \\
\text { "Uncle Jan does not } \\
\text { weigh much } \\
\text { when he is } 40 \\
\text { years old." }\end{array}$ \\
\hline & 3 & $\begin{array}{l}\text { The starting point has } \\
\text { correctly and } \\
\text { completely been } \\
\text { described }\end{array}$ & $\begin{array}{l}\text { The starting point is correctly } \\
\text { and precisely interpreted and } \\
\text { included }\end{array}$ & $\begin{array}{l}\text { "At the age of } 25 \\
\text { Uncle Jan weighs } \\
80 \text { kilos." }\end{array}$ \\
\hline
\end{tabular}


graph" (2), because the former relates to a complete line graph while the latter only relates to one point in a line graph. Last, all weighted scores were added up for each student's test and divided by the maximum number of points, resulting in a score (a mark from 1 to 10) for each student. Cronbach's alpha computed on the posttest scores was .83, which indicates a good internal consistency. Because of the small group size, we just use descriptive statistics to compare pre- and posttest scores.

\section{Results}

In the first lesson, the teacher introduces the lessons as "language-math lessons": "And that's new. It's a bit of language, and a bit of mathematics, and a bit of a mix. We are actually also going to talk about the language of mathematics." The teacher also stresses that the purpose of the lessons is to learn to formulate precisely in mathematics: "What exactly do we want to say? So we will think about how to use language to tell things precisely."

\section{Phase 1: building the field}

In the first phase of the teaching and learning cycle, the focus was on exploring the domain of line graphs. The mathematical activities involved meaningful, rich, open problems that did not yet include ready-made mathematical models such as line graphs. For example, with reference to an unfinished table of sunflower height data, the students were asked to construct their own representation and answer the question: "Will this sunflower reach a height of three meters?" After an investigation in small groups, students presented their own constructions, followed by whole-class interaction. These mathematical activities promoted progressive mathematization (Treffers 1987) toward a line graph, which was indeed proposed by several students. During the first lessons, the teacher particularly focused on concrete concepts (e.g., horizontal axis, table, growth process) rather than on more abstract concepts (e.g., constant) and formulations ("the graph rises") as the latter involves a greater learning burden (Nation 2001; Pichette et al. 2012). The concrete concepts formed part of the learning goals of the first three lessons. Throughout the nine lessons, the teacher wrote both the concrete and the abstract words on a growing word list that was used in classroom interaction as a scaffolding device. Students were given agency to suggest adding relevant words to the list from the first lesson onward. The words on the list were discussed in a functional way; that is, to support speaking and writing in the language that helped students reason about line graphs in a mathematically adequate way. Abdul contributes to whole-class interaction three times in the first lesson. When the teacher asks Abdul to formulate more precisely (one of the scaffolding strategies), he asks: "What do you mean?" Apparently, it is unclear to him what is expected. This is understandable, as he is not yet familiar with the way in which language is centralized in the mathematics lessons. In the second lesson, Abdul's use of language is still hesitant, for example "how much it changes, from years, the height" (when the growth of a boy is discussed).

At the start of lesson 3, the teacher asks the students what they consider a suitable title for a line graph about the growth of a boy. She explains: "If you say 'Koen's 
height,' you have only said something about it. But you say slightly more when you talk about 'growth process.' Because: what do I see happening right in front of me then?" The teacher explains the importance of precise language in discussing the difference between height and growth process.

Regarding Abdul, lesson 3 shows remarkable progress concerning the amount of utterances (11) and the use of general academic and topic-specific language (cf. learning goal 3). The teacher's attention to formulating precisely is reflected in Abdul's search for the most adequate term when describing the growth of a sunflower (see Fig. 3): "growth process," "sunflower process," and "sunflower growth process" (general academic language). He also starts actively using the word list on the wall. The first topic-specific word for graph descriptions emerges in lesson 3 in the context of growth of a sunflower: constant (L2). He uses this word, however, without embedding it in a sentence. In response to him, the teacher uses the scaffolding strategy of reformulating (RefExt): "Indeed, the graph goes constant." In the interview after lesson 3, Abdul uses the term constant again. He defines it as "stay on the same line" and does not yet demonstrate an adequate use of this topic-specific word.

\section{Phase 2: modeling the genre}

From the fourth lesson onward, the instructional activities predominantly focused on modeling the language required for describing and interpreting line graphs. In this phase, the structure features and linguistic features were explicitly addressed in instructional activities so as to explicitly model speaking and writing about line graphs. An example of a recurring modeling activity included the use of writing frames, which were also used as speaking frames in whole-class interaction in this research. The frames can be seen as templates to support students' speaking or writing, which include the staged character of the language to be developed (see Fig. 4 for an example): Other activities include discussion of exemplary line graph descriptions and discussion of students' own line graph descriptions (spoken as well as written). The teacher repeatedly discussed the need to formulate precisely so as to understand each other's contributions to mathematical discussions. She also started to attend to different features of the more "formal" language required in mathematics lessons (for instance

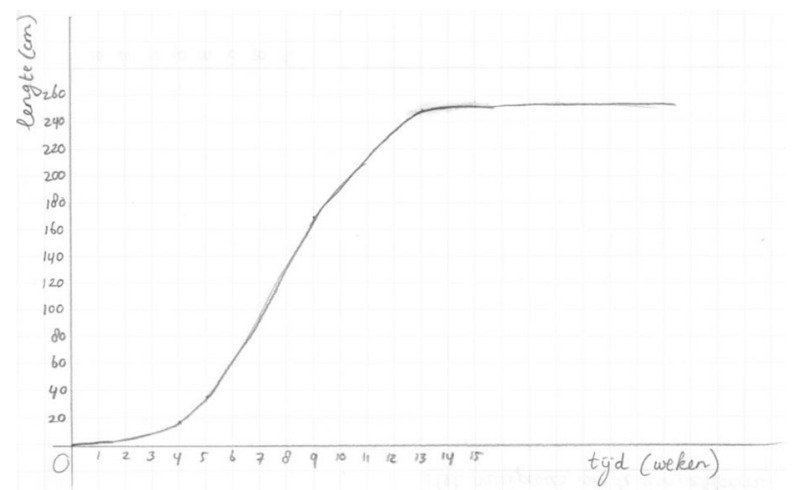

Fig. 3 Line representing the growth of a sunflower, used in lesson 4 ( $x$-axis is time (tijd) in weeks and $y$-axis is height (lengte) in $\mathrm{cm}$ ) 


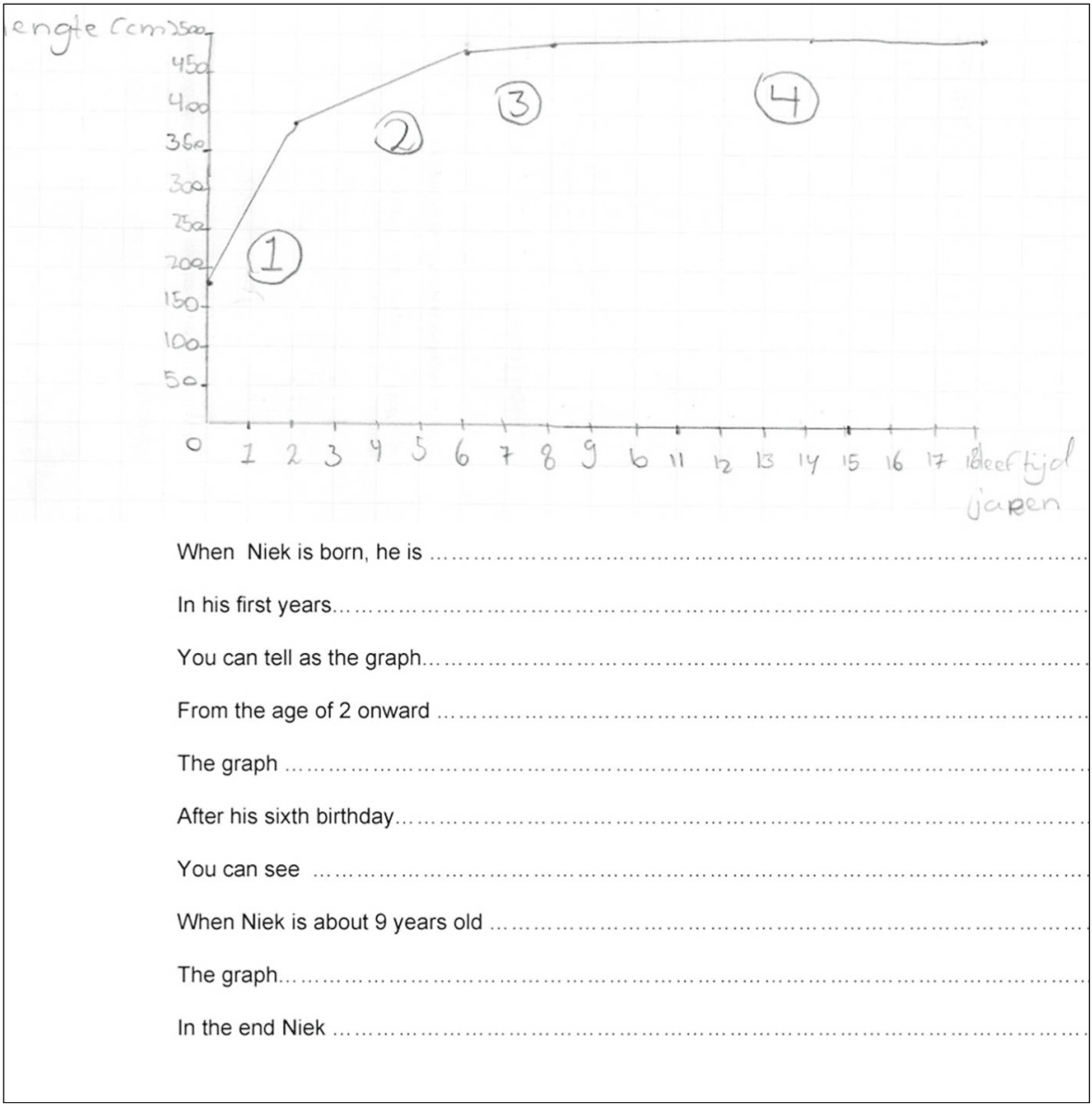

Fig. 4 Line graph discussed in lesson 5 with reference to a statement expressed by "Tom Talkative" (Piet Praatjes). "From two and six years Niek grows a little less fast. The graph is some less steep up". Lengte means height (y-axis), and leeftijd in jaren means age in years $(x$-axis). The text below forms an example of a writing frame accompanying the line graph as used in a subsequent instructional activity in the same lesson

"the height of the sunflower gradually increases") and the informal language used in daily life. The teacher called the latter "the language I can speak in my little kitchen garden," giving the example of "then it was smaller and then it was bigger."

At the beginning of lesson 4, the teacher recapitulates with the students which steps are involved in constructing a line graph (e.g., drawing the axes). Abdul shows slightly more advanced use of topic-specific language embedded in longer sentences during this activity (cf. learning goal 3). He makes use of mathematical terms such as horizontal axis that were among the learning goals of the first lessons, as in the following fragment:

Teacher So we have drawn a coordinate system (points to both axes). And what did we do subsequently? ... Then what did we do?

Abdul Weeks along, weeks along, write down weeks along the horizontal axis. 
A little later during the same activity, he contributes to the discussion: "Along the vertical axis you had to write down centimeters." Furthermore, he uses the topicspecific word constant again (L2), but this time reformulates his own utterance (instead of the teacher): "Constant, it goes constant." However, he still demonstrates difficulty with the word's meaning, as he says: "Miss, constant, then it goes higher up."

The activity concerning the line graph (see Fig. 3) is extended by modeling how a line graph can be divided into segments and how these can be described in terms of reality and in terms of the graph's course, using respectively general academic or topicspecific language (S1, S2, L1, L2). First, the teacher and students divide the line graph into segments by fixing strings on the whiteboard on those spots where the students and the teacher agree about the line graph's changing direction. Second, student utterances derived from their written graph descriptions made during a previous lesson are used as input for discussing and describing the three segments. These utterances are presented in PowerPoint as anonymous statements about the graph, and for each statement, the students are asked: "Is this statement correct?" During this activity, Abdul comes to understand that a line graph consists of several segments and he also starts to reason around the concept of constant in an adequate way, without scaffolding by the teacher: "[...] Bigger and bigger, but at two, two meter sixty, it just stays constant." The teacher explained the overall purpose of these activities as follows: "When I cut the graph in pieces, then I can actually tell something about one particular piece."

After the activities of recapitulating the construction of a line graph and modeling how to describe and interpret the different segments of the line graph, a few students are asked to "tell the graph's story in mathematical language." Abdul is in charge of the graph's second and third segments (see Fig. 3). He refers to the course of the graph (S2) but not yet to the represented reality in his description (S1). In his verbal description, he employs the word gradually for the first time (L2, L3; cf. learning goal 2). When this concept is introduced earlier in the lesson, the teacher points out how a word like gradually can mark the difference between two kinds of rising: "It rises, but this kind of rising is different than that kind of rising, isn't it?" This explanation relates to the distinction between gradations of steepness and their mathematical meaning (learning goal 2).

During lesson 4, Abdul further adequately uses the general academic phrase "to change direction," which the teacher repeats as an exemplary utterance (RepCor):

\footnotetext{
Yassin The sunflower grows gradually (points to the first segment of the graph). Is mathematical language like this? (Teacher nods.) Rises gradually. And then here (points to the second segment of the graph), then it grows fast. Yes, it grows fast. And that was it.

Teacher All right. And you can tell from the graph because... (StrucFea)?

Yassin Because it, that line, it just shows that it grows very fast.

Teacher And that, what would we call that in mathematical language? (LingFea)

Oussana Rise.

Teacher It rises quickly (RefExt). OK. Abdul, next two ones.

Abdul Here you can see that it changes direction again (holds his fingers at the point where the second string cuts through the line graph), it goes little more to the right. And then it rises again to thirteen (moves his finger along the line graph until he meets the next string). And then, it rises gradually up to constant.
} 


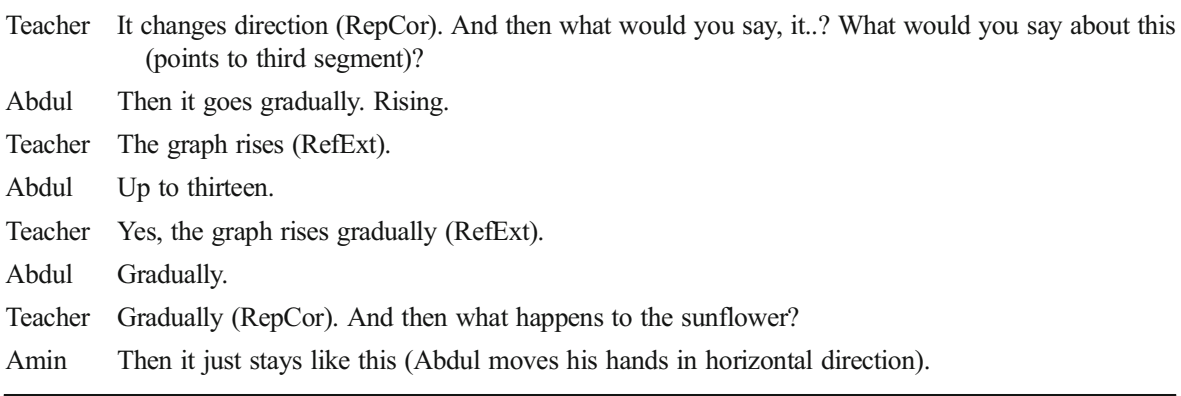

The interaction fragment shows that Abdul still seems to struggle with the meaning of gradually (L2, L3), despite the attention paid to it by the teacher. The meaning of growth process (a key word in the building the field phase), however, seems to be understood slightly later in the same lesson. This difference can be explained by the greater learning burden of the aforementioned abstract words that pose more conceptual demands on second language learners than concrete words (such as horizontal axis).

From lesson 5 onward, Abdul's language proficiency increases, although not in a linear way. During lesson 5, Abdul participates less frequently than in the lessons before and after (three contributions), and his contributions are less proficient. In the modeling activity represented in Fig. 4, the teacher and students again discuss student utterances from a previous lesson. These utterances are attributed to an imaginary child, Tom Talkative (in Dutch: Piet Praatjes). Each utterance is about one segment of a line graph representing a giraffe's growth and can be reformulated into more precise wordings (in terms of structure and linguistic features). During this activity, Abdul has trouble correcting Tom Talkative's utterances and seems not yet able to distinguish between topic-specific language and general academic language for the graph's course and reality, respectively (L1 and L2; learning goals 1 and 2). Moreover, he struggles with the correct use of temporal prepositions for either segments or points in the graph (L4 and L5; learning goal 3). This hinders his adequate mathematical interpretation as he does not dispose of the linguistic tools to make a distinction between points in the graph (moments) and segments of the graph (periods). Furthermore, his utterances are shorter than before, as shown in "here" or "the horizon..." He still seems uncertain about the meaning of constant, as he uses it for a segment of the graph that gradually rises in the following sentence: "After he has turned six, after six, it stays, the graph stays constant." This erroneous use of constant may illustrate the non-linear nature of (second) language development. Furthermore, it can be explained by the aforementioned various learning burdens of the concepts involved.

During lesson 6, Abdul explains the rise of a line graph representing the sale of swimming trunks as follows: "More swimming trunks are sold in June. Because then it is almost, it is almost summer holidays by then. And then they actually want to go swimming." The teacher first responds by saying that it is quite smart to think of a reason for the sudden rise the graph shows. However, she also stresses that opinions and conjectured causalities should not be included in the curriculum genre of a graph description: "A description should be very precise. 
And what Abdul just said, although very important, is not to be included in a description. In descriptions there are no opinions, nice stories, remarks about the weather outside and so on." A remarkable step in Abdul's language proficiency is his inclusion of reality (swimwear sold in June) in his graph description (learning goal 1). In this respect, Abdul seems to have benefited from the earlier lessons and scaffolding strategies directed at this structure feature (S1).

In lesson 6, Abdul still struggles with the use of temporal prepositions for points and segments in the graphs, but his proficiency concerning temporal prepositions (L4 and L5) is better in lessons 7 and 8 (learning goal 3). In lesson 7, he adequately responds to the teacher's scaffolding strategy, "Is it thirty till thirty five?", by saying "from." This illustrates Abdul is becoming familiar with the combination from ...to for describing periods in time (segments of the graph). It is also in lesson 7 that the teacher and the students have a meta-discussion on the use of temporal prepositions, which increases students' sense of the need to use them adequately. One of the pupils points out that temporal prepositions are often used incorrectly: "But almost everybody says so. [...] Even the teacher does it wrong sometimes." Then, the teacher acknowledges that she also makes mistakes. "But it is not about whether we are allowed to make mistakes or not, but about reflecting on your own use of language: How can I do it in a better way?" She then asks the students why she asks herself that question. One boy explains: "Then people start talking good language with you. Then they talk 'social language' to you or something like that." It is here that a student for the first time explicitly attends to the social benefits of using language in a functional and adequate way.

\section{Phase 3: joint construction}

In the joint construction phase, the teacher and students collaboratively formulate a line graph description. During this activity, the teacher is to scaffold students' contributions toward adequate use of structure and linguistic features. In our lesson series, the phase of joint construction was enacted in two different ways: in terms of jointly constructing verbal text in the curriculum genre without writing sentences down as well as with the teacher as a scribe writing down text on the whiteboard. The former seemed a suitable preparation for the latter. During the verbal joint construction of text in lesson 8, Abdul precisely and correctly describes a line graph's segment in terms of reality, this time using temporal prepositions adequately without the teacher's scaffolding (learning goals 1 and 3): "From his 20th to his 25th Uncle Kees slowly starts to lose weight" (S1, S2, L1, L5). This sentence further includes his first expression of gradation in terms of changes in reality (L3; learning goal 2). He also adequately formulates a sentence about the graph's course: "And then the graph stays constant." However, in a collaborative joint construction of written text later in the same lesson, Abdul again confuses reality and the graph's course: "The people at the station rise." The interviews held with Abdul after the last lessons show a similar development. On the one hand, Abdul clearly has become more proficient in the language required to interpret line graphs. On the other hand, he still demonstrates slight relapses in language production and shows misunderstanding of more abstract words. Abdul's development, therefore, signifies both the earlier mentioned long-term and nonlinear nature of language development and the complexity involved in reasoning about line graphs. 


\section{Phase 4: independent writing}

Independent writing and another written joint construction were enacted in lesson 9. Abdul was absent in this lesson, but he did perform independent writing during the posttest. Abdul scored 2.6 out of 10 at the pretest (among the lowest of the classroom) and 6.8 out of 10 at the posttest (just above average) - a difference of 4.2. Only three students made a bigger leap. The comparison of pre- and posttest scores for the whole class yields a difference of 2.89 on a scale up to 10 (see Table 4).

\section{Discussion}

\section{Summary}

In this paper, we asked: How can genre pedagogy be used to promote student proficiency in the language required to interpret line graphs? We answered this question in two steps. First, the rationale as informed by genre pedagogy was summarized in the "Theoretical background of the design and enactment" section. Second, the focused case study illustrated how the approach was enacted and Abdul became more proficient over time against the background of the intervention as inspired by genre pedagogy (in particular the teaching and learning cycle). The case study showed how Abdul increasingly demonstrated adequate and independent employment of the language for interpreting line graphs, but also kept struggling with, for instance, the meaning and use of more abstract words (e.g., constant and gradually). It further demonstrated that a student whose linguistic starting level is on the low side can improve in a relatively short amount of time.

Without a comparison group, we are not making claims about whether our approach leads to better learning results than other approaches. We consider the results only to be an indication of an exploratory proof of principle: It is possible to help fifth- and sixthgrade students become much more proficient in domain-specific language. We interpret this finding as a sign of feasibility of promoting domain-specific language in classrooms and an initial empirical justification for focusing on structure features and linguistic features as in Table 1, in combination with using particular activities and scaffolding strategies. With this answer about the how and that of our approach, we think we address a concern in relation to the discursive turn in mathematics education that has so far received little attention: How to design and enact language-oriented approaches?

Our research took place in a multilingual school. In the classroom studied, 19 out of 22 students had a migrant background and many of them spoke Berber or Turkish at home. Because the three native students also benefited from the intervention, we

Table 4 Comparison of the pre- and posttest results on the relevant item

\begin{tabular}{llll}
\hline & Pretest, $M(\mathrm{SD})$ & Posttest, $M(\mathrm{SD})$ & Difference, $M(\mathrm{SD})$ \\
\hline Class $(N=22)$ & $3.73(0.74)$ & $6.63(1.71)$ & $2.89(1.62)$ \\
\hline
\end{tabular}

The maximum score was 10 
suggest that our approach is not solely suitable for minority students but has a much wider scope. After all, all mathematics learners are - to some extent-learning a new language (Gibbons 2002; Morgan 2007).

\section{Potential pitfalls of using genre pedagogy and how to avoid them}

From the literature on genre pedagogy and language in mathematics education, we foresee a few potential pitfalls of focus on language or, more generally, on genres. First, if we consider language or a genre a norm of how to speak and write in a particular domain, this norm could lead to deficit views on the bilingual learner (Moschkovich 2010), as it could focus attention too much on language proficiency (Gorgorió and Planas 2001; Setati and Adler 2000). Second, teachers and students may initially view language or genre as a set of words and phrases (Morgan 2005). Such "static" views have been criticized by scholars who argue that genre pedagogy constrains students' self-expression and creativity (Knapp and Watkins 2005). As a result, it would induce formulaic, empty language use (e.g., Coe 2002). In Tardy's (2006) words, these counter voices are justifiable and necessary to warn researchers, educators, and teachers how not to focus on language. We now argue how the potential pitfalls can be avoided.

The norm issue is related to Adler's (2001) dilemma of transparency: the dilemma of whether or not to explicitly and visibly focus on topic-specific language required in the classroom. Although she acknowledges the potential benefits of learner-centered, implicit approaches as they create space for students' creativity and meaning-making, she states that such practices still rely on students' communicative competence- thus also ask for and explicitly focus on language development. Concerning criticism on genres being used as a norm, we stress that promoting students' academic language development, as with other types of instructional endeavors, unavoidably holds a normative nature (Macbeth 2010). We think that there is nothing wrong with centralizing norms, as long as these norms emerge out of an agreed sense of what can be said or done in a classroom (Van Oers 2001). To this end, it is worth exploring whether students can reflect on language features themselves (cf. Hyland 2004). During the phase of modeling the genre, for instance, students could compare different texts to derive their "own" formulations of language features. These features, however, still need to be well defined in advance.

As Morgan (2005) wrote, language entails more than vocabulary. The notion of genre in a more educationally phrased definition directs designers' and teachers' attention to a broader range of things that matter. For example, as a complement to linguistic features, there are also structure features such as the stages involved in interpreting and describing a line graph. By formulating a small set of relevant linguistic and structure features, we as design researchers support teachers to help their students talk mathematically.

\section{Recommendations and future research}

This study has focused on one particular domain of mathematics, line graphs. Hence, a recommendation for future research is to design for other domains too. We hope that this can advance our understanding of how a focus on language use can become a part of educational practice and design. Our work has pointed to the potential of focusing on 
language use, especially in the context of multilingual and language-weak classrooms, and of specifying structure and linguistic features of the language to be developed by students. We hope this idea will be taken up by others for other topics and subjects so as to help students become proficient in topic-specific language and become more successful in learning.

Open Access This article is distributed under the terms of the Creative Commons Attribution 4.0 International License (http://creativecommons.org/licenses/by/4.0/), which permits unrestricted use, distribution, and reproduction in any medium, provided you give appropriate credit to the original author(s) and the source, provide a link to the Creative Commons license, and indicate if changes were made.

\section{References}

Adler, J. (2001). Teaching mathematics in multilingual classrooms. Dordrecht: Kluwer.

Bakker, A., \& Smit, J. (2016). Theory development in design-based research: an example about scaffolding mathematical language. In S. Doff \& R. Komoss (Eds.), How does change happen? (pp. 109-124). Wiesbaden: Springer.

Bakker, A., Smit, J., \& Wegerif, R. (2015). Scaffolding and dialogic teaching in mathematics education: introduction and review. ZDM, 47(7), 1047-1065.

Bickmore-Brand, J., \& Gawned, S. (1990). Scaffolding for improved mathematical understanding. In J. Bickmore-Brand (Ed.), Language in mathematics (pp. 43-58). Carlton South: Australian Reading Association.

Campbell, A. E., Adams, V. M., \& Davis, G. E. (2007). Cognitive demands and second-language learners: a framework for analyzing mathematics instructional contexts. Mathematical Thinking and Learning, 9, 3-30.

Chapman, A. (1997). Towards a model of language shifts in mathematics learning. Mathematics Education Research Journal, 9, 152-173.

Chapman, A. P. (2003). Language practices in school mathematics: a social semiotic approach. Lewiston: Edwin Mellen.

Chodorow, M., Gamon, M., \& Tetreault, T. (2010). The utility of article and preposition error correction systems for English language learners: feedback and assessment. Language Testing, 27(3), 419-436.

Clarke, D. (1988). The mathematics curriculum and teaching program professional development package: assessment alternatives in mathematics. Carlton, Victoria: Curriculum Development Centre.

Cobb, P., \& Yackel, E. (1996). Constructivist, emergent, and sociocultural perspectives in the context of developmental research. Educational Psychologist, 31, 175-190.

Coe, R. (2002). The new rhetoric of genre: writing political beliefs. In A. Johns (Ed.), Genre in the classroom: multiple perspectives (pp. 197-210). Mahwah: Lawrence Erlbaum.

Cohen, J. (1988). Statistical power analysis for the behavioural sciences (2nd ed.). Mahwah: Lawrence Erlbaum Associates.

Cope, B., \& Kalantzis, M. (Eds.). (1993). The powers of literacy: a genre approach to teaching writing. London: Falmer.

Derewianka, B. (1990). Exploring how texts work. Sydney: Primary English Teaching Association (PETA).

Ellerton, N. F., \& Clarkson, P. C. (1996). Language factors in mathematics teaching and learning. In A. J. Bishop, K. Clements, C. Keitel, J. Kilpatrick, \& C. Laborde (Eds.), International handbook of mathematics education (pp. 987-1033). New York: Springer.

Ellerton, N. F., \& Clements, M. A. (1991). Mathematics in language: a review of language factors in mathematics learning. Geelong: Deakin University.

Ferrari, P. L. (2004). Mathematical language and advanced mathematics learning. In M. Johnsen Hoines \& A. Berit Fugelstad (Eds.), Proceedings of the 28th conference of PME (pp. 383-390). Bergen: Bergen University College.

Gibbons, P. (2002). Scaffolding language, scaffolding learning: teaching second language learners in the mainstream classroom. Portsmouth: Heinemann.

Gibbons, P. (2009). English learners academic literacy and thinking. Portsmouth: Heinemann.

Gorgorió, N., \& Planas, N. (2001). Teaching mathematics in multilingual classrooms. Educational Studies in Mathematics, 47, 7-33. 
Gutiérrez, K. D., Sengupta-Irving, T., \& Dieckmann, J. (2010). Developing a mathematical vision. In J. N. Moschkovich (Ed.), Language and mathematics education: multiple perspectives and directions for research (pp. 29-71). Charlotte: Information Age.

Hyland, K. (2004). Genre and second language writing. Ann Arbor: University of Michigan Press.

Hyland, K. (2007). Genre pedagogy: language, literacy, and L2 writing instruction. Journal of Second Language Writing, 16, 148-164.

Knapp, P., \& Watkins, M. (2005). Genre, text, grammar: technologies for teaching and assessing writing. Sydney: UNSW.

Lampert, M., \& Blunk, M. L. (1998). Talking mathematics in school: studies of teaching and learning. Cambridge: Cambridge University Press.

Leinhardt, G., Zaslavsky, O., \& Stein, M. K. (1990). Functions, graphs, and graphing: tasks, learning, and teaching. Review of Educational Research, 60(1), 1-64.

Lovitt, C., \& Clarke, D. (2011). The designer speaks. The features of a rich and balanced mathematics lesson: teacher as designer. Educational Designer, 1(4). http://www.educationaldesigner.org/ed/volume1/issue4/article15/.

Macbeth, K. P. (2010). Deliberate false provisions: the use and usefulness of models in learning academic writing. Journal of Second Language Writing, 19, 33-48.

Martin, J. R. (1989). Technicality and abstraction: language for the creation of specialised knowledge. In F. Christie (Ed.), Writing in schools (pp. 36-44). Geelong: Deaking University Press.

Martin, J. R. (2009). Genre and language learning: a social semiotic perspective. Linguistics and Education, $20,10-21$.

Martin, J. R., \& Rose, D. (2008). Genre relations: mapping culture. London: Equinox.

Mercer, N., \& Littleton, K. (2007). Dialogue and the development of children's thinking: a sociocultural approach. London: Routledge.

Monk, S. (2003). Representation in school mathematics: learning to graph and graphing to learn. In J. Kilpatrick, W. G. Martin, \& D. Schifter (Eds.), A research companion to principles and standards for school mathematics (pp. 250-262). Reston: National Council of Teachers of Mathematics.

Morgan, C. (2005). Words, definitions and concepts in discourses of mathematics, teaching and learning. Language and Education, 19(2), 103-117.

Morgan, C. (2007). Who is not multilingual now? Educational Studies in Mathematics, 64, 239-242.

Moschkovich, J. N. (1996). Moving up and getting steeper: negotiating shared descriptions of linear graphs. The Journal of the Learning Sciences, 5(3), 239-277.

Moschkovich, J. N. (2002). A situated and sociocultural perspective on bilingual mathematical learners. Mathematical Thinking and Learning, 4, 189-212.

Moschkovich, J. N. (2010). Language and mathematics education: multiple perspectives and directions for research. Charlotte: Information Age.

Mousley, J., \& Marks, G. (1991). Discourses in mathematics. Geelong: Deaking University Press.

Mushin, I., Gardner, R., \& Munro, J. M. (2013). Language matters in demonstrations of understanding in early years mathematics assessment. Mathematics Education Research Journal, 25, 415-433.

Nathan, M. J., \& Kim, S. (2007). Pattern generalization with graphs and words: a cross-sectional and longitudinal analysis of middle school students' representational fluency. Mathematical Thinking and Learning, 9(3), 193-219.

Nation, I. S. P. (2001). Learning vocabulary in another language. Cambridge: Cambridge University Press.

Pichette, F., De Serres, L., \& Lafontaine, M. (2012). Sentence reading and writing for second language vocabulary acquisition. Applied Linguistics, 33(1), 66-82.

Pimm, D. (1987). Speaking mathematically: communication in mathematics classrooms. London: Routledge.

Planas, N., \& Setati, M. (2009). Bilingual students using their languages in the learning of mathematics. Mathematics Education Research Journal, 21(3), 36-59.

Prediger, S., \& Wessel, L. (2013). Fostering German-language learners' constructions of meanings for fractions-design and effects of a language- and mathematics-integrated intervention. Mathematics Education Research Journal, 25, 435-456.

Expertgroep Taal en Rekenen. (2009). Referentiekader taal en rekenen [reference framework language and mathematics]. Enschede: SLO.

Rothery, J. (1996). Making changes: developing an educational linguistics. In R. Hasan \& G. Williams (Eds.), Literacy in society (pp. 86-123). London: Longman.

Schleppegrell, M. J. (2007). The linguistic challenges of mathematics teaching and learning: a research review. Reading and Writing Quarterly, 23(2), 139-159.

Setati, M., \& Adler, J. (2000). Between languages and discourses. Educational Studies in Mathematics, 43, 243-269. 
Sfard, A. (2008). Thinking as communicating: human development, the growth of discourses, and mathematizing. Cambridge: Cambridge University Press.

Shah, P., \& Hoeffner, J. (2002). Review of graph comprehension research: implications for instruction. Educational Psychology Review, 14(1), 47-69.

Smit, J., \& Van Eerde, H. A. A. (2011). A teacher's learning process in dual design research: learning to scaffold language in a multilingual mathematics classroom. ZDM, 43(6-7), 889-900.

Smit, J., \& Van Eerde, H. A. A. (2013). What counts as evidence for the long-term realisation of whole-class scaffolding? Learning. Learning, Culture and Social Interaction, 2(1), 22-31.

Smit, J., Van Eerde, H. A. A., \& Bakker, A. (2013). A conceptualisation of whole-class scaffolding. British Educational Research Journal, 39(5), 817-834.

Spycher, P. (2007). Academic writing of adolescent English learners: learning to use "although". Journal of Second Language Writing, 16, 238-254.

Tardy, C. M. (2006). Researching first and second language genre learning: a comparative review and a look ahead. Journal of Second Language Writing, 15, 79-101.

Treffers, A. (1987). Three dimensions: a model of goal and theory description in mathematics instruction-the Wiskobas project. Dordrecht: Reidel.

Van Oers, B. (2001). Educational forms of initiation in mathematical culture. Educational Studies in Mathematics, 46, 59-80.

Warren, E., \& Miller, J. (2013). Young Australian indigenous students' effective engagement in mathematics: the role of language, patterns, and structure. Mathematics Education Research Journal, 25(1), 151-171.

Wilkinson, L. C. (2015). Introduction [to the special issue language of learning mathematics]. The Journal of Mathematical Behavior, 40, 2-5.

Wood, D., Bruner, J., \& Ross, G. (1976). The role of tutoring in problem solving. J Child Psychol Psychiatry, 17, 89-100. 